\title{
Carbon dioxide production as an indicator of Aspergillus flavus colonisation and aflatoxins/cyclopiazonic acid contamination in shelled peanuts stored under different interacting abiotic factors
}

\author{
Garcia-Cela, E. ${ }^{1}$, Gari Sanchez, F.J', Verheecke-Vaessen, C. ${ }^{1}$, Medina, A. ${ }^{1}$, Sulyok, M. ${ }^{2}$, \\ Kruska, R. ${ }^{2}$, Magan, N. ${ }^{1}$ \\ $1 \quad$ Applied Mycology Group, Environment and AgriFood Theme, Cranfield University, \\ Cranfield, Beds. MK43 AL5, U.K; m.e.garcia-cela@cranfield.ac.uk; arelgar17@gmail.com; \\ C.Verheecke@cranfield.ac.uk; a.medinavaya@cranfield.ac.uk; n.magan@cranfield.ac.uk.
}

2 Institute of Bioanalytics and Agro-Metabolomics, Department of Agrobiotechnology (IFA-Tulln), University of Natural Resources and Life Sciences, Vienna, Konrad Lorenzstr. 20, A-3430 Tulln, Austria michael.sulyok@boku.ac.at; rudolf.krska@boku.ac.at

\begin{abstract}
Aspergillus flavus is the main xerophylic species in stored peanuts often resulting in contamination with aflatoxins (AFs) and cyclopiazonic acid (CPA). This study evaluated the relationship between storage of shelled peanuts under interacting abiotic conditions on (a) the temporal colonisation kinetics and cumulative respiration rates, (b) quantified the effect on dry matter losses (DMLs) and (c) quantify accumulation of aflatoxin $\mathrm{B}_{1}\left(\mathrm{AFB}_{1}\right)$ and CPA. Both naturally contaminated and inoculated peanuts with $A$. flavus conidia were stored for 7 -days under different water activity $\left(a_{w} ; 0.77-0.95\right)$ and temperature levels $\left(20-35^{\circ} \mathrm{C}\right)$. Gas Chromatography (GC-TCD) was used to measure the temporal respiration rates $(R)$ and the total accumulated $\mathrm{CO}_{2}$ production. Mycotoxin contamination was quantified at the end of the storage period by LC-MS/MS. There was an increase in the temporal $\mathrm{CO}_{2}$ production rates in wetter and warmer conditions in all treatments, with the highest respiration in the $0.95 \mathrm{a}_{\mathrm{w}}$ treatments of stored peanuts $+A$. flavus inoculum at $30^{\circ} \mathrm{C}\left(2474 \mathrm{mg} \mathrm{CO}_{2} \mathrm{~kg}^{-1} \mathrm{~h}^{-1}\right)$. The DMLs were modelled to produce contour maps of the environmental conditions resulting in maximum/minimum losses. Maximum mycotoxin contamination was always at $0.95 \mathrm{a}_{\mathrm{w}}$ although optimal temperatures were different for $\mathrm{AFB}_{1}$ and $\mathrm{CPA}$. Thus, $30-35^{\circ} \mathrm{C}$ was optimum for CPA and $25-30^{\circ} \mathrm{C}$ for AFs. A significant positive correlation (Spearman $p<0.0001$ ) were found between $\log _{10} A F B$ and $\log _{10} D M L$ in both naturally contaminated stored peanuts $\left(r^{2}=0.7744\right)$ and that inoculated with $A$. flavus $\left(r^{2}=0.8464\right)$. Small dry matter losses $(0.56 \%)$ resulted in $\mathrm{AFB}_{1}$ contamination above the $\mathrm{EU}$ legislative limits. Real time $\mathrm{CO}_{2}$ monitoring is a powerful tool to provide an early indication of biological activity, our results shower a correlation with high $\mathrm{CO}_{2}$ production fungal growth and mycotoxin accumulation. These results provide valuable information for the creation of a database for the development of a postharvest decision support system for determining relative risks of contamination with these mycotoxins in stored shelled peanuts.
\end{abstract}

Highlights ( 3 to 5 / 85 character per bullet point including spaces)

$\checkmark$ Higher optimum temperature for $A$. flavus growth $\left(30-35^{\circ} \mathrm{C}\right)$ than for $\mathrm{AFB}_{1}$ production (25$\left.30^{\circ} \mathrm{C}\right)$

$\checkmark$ Optimum cyclopiazonic acid production was at $\left(30-35^{\circ} \mathrm{C}\right)$, with none at $0.90 \mathrm{a}_{\mathrm{w}}$

$\checkmark$ Dry matter losses varied from $0.3-17 \%$ at $0.90-0.95 a_{w}$ in stored peanuts depending on the temperature. 
$\checkmark$ Dry matter losses can be used as a sensitive early indicator of initiation of fungal spoilage

$\checkmark$ Dry matter losses due to fungal activity $(0.56 \%)$ resulted in aflatoxin contamination exceeding EU limits

\section{Keywords (6 keywords)}

Groundnuts; temperature; water activity; mycotoxins; dry matter losses, storage, food safety

1. Introduction

Peanuts (Arachis hypogaea L.) also known as groundnuts, is a legume that originated in South America. Peanut plants are grown widely in China, India, Africa and the USA. Peanut world production in 2016 was approx. 43.9M tonnes (Food and Agriculture Organisation of the United Nations, 2018). Peanut crops are very susceptible to fungal diseases, especially by mycotoxigenic fungi during the pod filling phase at pre-harvest, particularly during drought stress episodes (Paterson and Lima, 2011). Subsequently, poor drying and storage can result in further mycotoxin contamination, as peanuts are hygroscopic and absorb moisture easily. Fusarium, Penicillium, and Aspergillus species are commonly isolated from peanuts during the whole production phase from growth to storage. Aspergillus flavus infection occurs during the pre-harvest stage but colonisation can also occur during drying and storage, when the most commonly isolated species have been reported (Atayde et al., 2012; Gonçalez et al., 2008; Sultan and Magan, 2010; Zorzete et al., 2011, 2013). This results in significant contamination with toxic secondary metabolites, especially aflatoxins (AFs) and cyclopiazonic acid (CPA). Such contamination has major impacts on the quality of the product and the potential for its export from producer countries resulting in significant economic impacts, especially in Lower Middle Income Countries (LMICs) (Atayde et al., 2012; de Souza et al., 2014; Zorzete et al., 2011, 2013).

Peanuts like other edible seeds respire at very low levels under safe storage and reduced water availability conditions (water activity, $a_{w} ;<0.70 a_{w}=8 \%$ moisture content (m.c.). Under these conditions, while fungal contaminants remain viable, they are unable to initiate spoilage or any additional toxin contamination (Fleurat-Lessard, 2017; Paterson and Lima, 2011). However, poor storage conditions or inadequate silo hygiene can lead to the introduction of water from outside, boosting the pest and disease activity. This biological activity can lead to pockets of spoilage resulting in toxin contamination. This also results in an increase in the respiration of the stored peanuts and of the associated mycobiota. Spoilage fungi are able to utilise the lipids present, leading to a deterioration in quality and associated dry matter losses (DMLs) (Seitz et al., 1982). Saul and Lind (1958) were the first to correlate the impact the respiration $\left(\mathrm{CO}_{2}\right.$ production) and DMLs due to fungal colonisation and mycotoxin production. 
According to Seitz et al. (1982), mould colonisation increases the DML during storage at a rate dependent on the prevailing m.c., temperature, level of kernel damage and the fungal community present on the phyllosphere surfaces of the peanuts.

Recent studies have shown that changes in $\mathrm{CO}_{2}$ production during storage of cereals, including maize, wheat, oats and rice can be used as an indicator of DML, as well as the relationship with mycotoxin contamination (Garcia-Cela et al., 2018; Garcia-Cela et al., 2019; Martín Castaño et al., 2017ab; Mylona et al., 2012 ab; Mylona and Magan, 2011). In these studies it was found that it is possible to use the progressive increase in the aerobic respiration rate under increasingly conducive interacting abiotic factors. This is related to mould growth, as their activity leads to an oxidation of carbohydrates/lipids and hence $\mathrm{CO}_{2}$ production. Therefore, it can be linked to the quality losses as DML percentages. Respiration rates (R) using Gas Chromatography and the associated DMLs can be used to establish an "index of risk in storage" to predict overall quality changes and mycotoxin contamination in stored cereals and nuts (Magan et al., 2010).

Previously, DML values as low as $0.04,1$ and $2 \%$ indicated impacts on seed germination and risk of mycotoxin contamination in the context of the EU legal maximum limits (Garcia-Cela et al., 2018; Garcia-Cela et al., 2019; Lacey et al., 1994; Martín Castaño et al., 2017ab; Mylona et al., 2012b; Mylona and Magan, 2011; White et al., 1982). However, very little data is available on nuts, especially peanuts, although studies by Mylona (2012a) examined A. flavus and $\mathrm{CO}_{2}$ production in hazelnuts, showing that very small DMLs resulted in aflatoxin $\mathrm{B}_{1}\left(\mathrm{AFB}_{1}\right)$ contamination exceeding the EU legislative limits.

Indeed, subsequent studies have suggested that $\mathrm{CO}_{2}$ production could be a very powerful tool for the early prediction of the initiation of spoilage mould activity and therefore mycotoxin contamination of wheat, maize and rice (Mylona et al., 2012b; Martín Castaño et al., 2017a,b). This approach could have benefits in the development of sensing systems for the early indication of spoilage initiation, based on real time temporal monitoring of $\mathrm{CO}_{2}$.

Thus, the aims of our study were to (a) examine temporal respiration $(R)$ and cumulative total $\mathrm{CO}_{2}$ production by stored naturally contaminated shelled peanuts or those artifcially inoculated with $A$. flavus conidia stored under different conditions of $a_{w}(0.77-0.95)$ and temperatures (20$35^{\circ} \mathrm{C}$ ) conditions; (b) relate $\mathrm{R}$ production during storage to relative DMLs; (c) quantify AFs and CPA in all stored conditions; and (d) investigate the relationship between \%DMLs and $\mathrm{AFB}_{1}$ contamination relative to the EU legislative limits for food and feed use. The potential outcomes for using such data sets and models as a predictive tool of the relative risk of $\mathrm{AFB}_{1}$ contamination during storage of peanuts by monitoring of $\mathrm{CO}_{2}$ production are discussed. 


\section{Material and Methods}

\subsection{Fungal isolate}

An aflatoxigenic type strain of $A$. flavus (NRRL 3357; Northern Regional Research Laboratories (NRRL) of the US Department of Agriculture USDA, New Orleans) was used in this experiment. The strain was maintained in glycerol:water $(70: 30, \mathrm{v} / \mathrm{v})$ at $-20^{\circ} \mathrm{C}$ in the culture collection of the Applied Mycology Group, Cranfield University.

\subsection{Peanuts samples}

Shelled peanuts from China, were used as naturally contaminated peanuts for storage experiments. Water activity $\left(a_{w}\right)$ of both batches was 0.77 , and they were stored at $4^{\circ} \mathrm{C}$ in resealable zip-lock polyethene bags until their use.

\subsection{Peanut water activity adjustment}

Known volumes of sterile water $(0-2 \mathrm{~mL})$ were added to $5 \mathrm{~g}$ sub-samples of naturally contaminated peanuts in $40 \mathrm{~mL}$ glass Universal bottles. These were sealed, shaken vigorously and stored overnight at $4^{\circ} \mathrm{C}$ to allow water absorption and equilibration. Samples were then equilibrated at room temperature $(T)$ before the measurement of $a_{w}$ values of each subsample, using the dew point/water activity meter AQUALAB Model Series 4TE (Decagon Instruments; Washington, USA). Water adsorption curves were determined by plotting the amounts of added water $(\mathrm{mL})$ against $a_{w}$ values measured. These curves were used to determine the exact quantities of water needed to reach the target $a_{w}$ levels for each set of experiments performed. After this, the m.c. of the samples was determined by drying them in an oven at $105^{\circ} \mathrm{C}$ for $16 \mathrm{~h}$.

\subsection{Inoculation and storage experiments carried out}

The $A$. flavus strain was sub-cultured on malt extract agar medium (MEA) in two $9 \mathrm{~cm}$ Petri dishes and incubated at $25^{\circ} \mathrm{C}$ for 7 days to obtain actively sporulating cultures. A sterile loop was used to remove some conidia from the culture and mix this with $9 \mathrm{~mL}$ sterile water containing $0.005 \%$ Tween 80 . The suspension was homogenised and adjusted with sterile water to obtain a final concentration of $1 \times 10^{4}$ spores $\mathrm{mL}^{-1}$ using a Thoma counting chamber (Marienfield superior, Germany).

Natural shelled peanut samples $(90 \mathrm{~g})$ were modified with sterile water $(-1 \mathrm{~mL}$ for spore inoculum), moisture adsorption curve, to obtain the target treatment $a_{w}$ levels $(0.95,0.90$, 
0.85 ), and stored at $4^{\circ} \mathrm{C}$ for $24 \mathrm{~h}$. Control treatment was unmodified peanuts at $0.77 \mathrm{a}_{\mathrm{w}}$. Four replicates $(5 \mathrm{~g})$ per treatment were placed in $40-\mathrm{mL}$ clear glass Volatile Organic Analysis (VOA) vials with sealable PTFE caps containing a silicone septum (23188 Supelco) to allow for later gas sampling from the headspace. Peanut samples corresponding to the same $a_{w}$ levels were incubated in 12-L polypropylene environmental chambers together with $2 \times 500$ $\mathrm{mL}$ beakers of glycerol/water solutions to maintain the target Equilibrium Relative Humidity $(E R H)$ of the atmosphere relative to each $a_{w}$ treatment value. Peanut samples were incubated for 7 days.

2.5. Respiration of peanuts stored under different water activity and temperature conditions

Treatments used in this study were temperatures of $20,25,30$ and $35^{\circ} \mathrm{C}$ and $\mathrm{a}_{w}$ levels of 0.77 0.88-0.90 and 0.95. Carbon dioxide $\left(\mathrm{CO}_{2}\right)$ production was measured every $24 \mathrm{~h}$. Sampling method used was that previously described by Mylona \& Magan (2011). The percentages of $\mathrm{CO}_{2}$ concentration were used to calculate (a) Respiration (R) rate in $\mathrm{mg} \mathrm{CO}_{2}\left(\mathrm{~kg} \mathrm{~h}^{-1}\right)$, (b) total cumulative production of $\mathrm{CO}_{2}$ after 7 days storage and (c) the total DMLs (Mylona and Magan, 2011a).

\subsection{Mycotoxin analysis}

\subsubsection{Sample preparation}

At the end of the experiment peanuts from the different treatments were dried at $60^{\circ} \mathrm{C}$ for 48 $\mathrm{h}$, milled and stored at $4^{\circ} \mathrm{C}$ until analysis. Between two and three grams of milled peanuts were used for mycotoxin extraction using 8 and $12 \mathrm{~mL}$ (peanuts powder/four times extract volume) of the extraction solvent (acetonitrile/water/acetic acid 79/20/1) followed by a $1+1$ dilution using acetonitrile/water/acetic 79/20/1. Five $\mu \mathrm{L}$ of the diluted extract were directly injected into the sampling port for LC-MS/MS analysis. For concentrations exceeding 500 $\mu \mathrm{g} \cdot \mathrm{kg}^{-1}$. The extract was further diluted $1+49$ and reanalysed.

\subsubsection{LC-MS/MS parameters}

LC-MS/MS screening of targeted fungal mycotoxins was performed with a QTrap 5500 LCMS/MS System (Applied Biosystems, Foster City, CA) equipped with a TurbolonSpray electrospray ionization (ESI) source and a 1290 Series HPLC System (Agilent, Waldbronn, Germany). Chromatographic separation was performed at $25^{\circ} \mathrm{C}$ on a Gemini C18-column, 150 x $4.6 \mathrm{~mm}$ i.d., $5 \mu \mathrm{m}$ particle size, equipped with a $\mathrm{C} 184 \times 3 \mathrm{~mm}$ i.d. security guard cartridge (all from Phenomenex, Torrance, CA, US). The chromatographic method as well as chromatographic and mass spectrometric parameters were previously described by Malachová et al. (2014).

Electrospray ionization (ESI-MS/MS) was performed in the time-scheduled multiple reaction monitoring (MRM) mode both in positive and negative polarities in two separate 
chromatographic runs per sample by scanning two fragmentation reactions per analyte. The MRM detection window of each analyte was set to its expected retention time \pm 27 and \pm 48 seconds in positive and negative mode, respectively.

Quantification was performed by external calibration using serial dilutions of a multianalyte stock solution made up of the following standards: $A F B_{1}$, aflatoxin $B_{2}\left(A F B_{2}\right)$ and $C P A$. The accuracy of the method has been verified on a continuous basis by regular participation in proficiency testing schemes (Malachova et al., 2015; Malachová et al., 2014).

\subsection{Statistical Analysis}

Statistical analysis was performed using package JMP® Pro 14 (SAS Institute Inc., 2016. Cary, NC, USA). Datasets were tested for normality and homoscedasticity using the ShapiroWilk and Levene test, respectively. When data failed the normality test, variable transformation was performed to try to improve normality or homogenise the variances. Transformed data were still not normally distributed and therefore the Wilconxon or Kruskal-Wallis test by ranks was used for the analysis of the data. Non-parametric comparisons for each pair using the Wilcoxon Method were used to find differences between groups.

Forward stepwise regression including all the linear, quadratic and the interaction terms (Equation 1) was used to obtain polynomial equations for DML with regard to the storage conditions $\left(\mathrm{a}_{\mathrm{w}}\right.$ and $\left.\mathrm{T}\right)$ for both naturally and contaminated shelled peanuts. Non significant terms ( $p$-value>0.05) were excluded. The assumptions of linearity and normally distributed residuals were assessed, producing normal plots of the residuals. Contour maps were built in JMP® Pro 14 using 5000 simulation data from predicted formula.

$$
D M L=b_{0}+b_{1} T+b_{2} a_{w}+b_{4} a_{w}^{2} \times T^{2}
$$

\section{Equation 1}

\section{Results and Discussion}

3.1. Impact of $\mathrm{a}_{\mathrm{w}}$ and temperature on the temporal and total accumulated $\mathrm{CO}_{2}$ in naturally and contaminated shelled peanuts with $A$. flavus inoculum

Overall, the respiration rates of artificially inoculated shelled peanuts with $A$. flavus inoculum increased after two days storage, depending on the $a_{w}$ and temperature treatment. Figure 1 shows the temporal (hourly) respiration rate $(\mathrm{R})$ and the total accumulated $\mathrm{CO}_{2}$ (cumulative $\mathrm{R} ; \mathrm{g} \mathrm{CO}_{2} \mathrm{~kg}^{-1}$ peanuts) at $30^{\circ} \mathrm{C}$ for the four different $\mathrm{a}_{\mathrm{w}}$ levels. In general, respiration in the stored peanuts at 0.77-0.90 $a_{w}$ was relatively low, regardless of the storage temperature. The highest respiration rates were at $0.95 \mathrm{a}_{\mathrm{w}}$ for the inoculated stored peanuts at $30^{\circ} \mathrm{C}(2474 \mathrm{mg}$ $\left.\mathrm{CO}_{2} \mathrm{~kg}^{-1} \mathrm{~h}^{-1}\right)$. Similar $\mathrm{CO}_{2}$ production levels were found at 30 and $35^{\circ} \mathrm{C}$ in both naturally $(2079$ and $\left.2281 \mathrm{mg} \mathrm{CO}_{2} \mathrm{~kg}^{-1} \mathrm{~h}^{-1}\right)$, and inoculated (2274 and $\left.2096 \mathrm{mg} \mathrm{CO}_{2} \mathrm{~kg}^{-1} \mathrm{~h}^{-1}\right)$. In other cereal commodities, $\mathrm{R}$ for shelled peanuts was also optimum at 0.95 aw in paddy rice, brown rice 
and maize when inoculated with A. flavus at $30-35^{\circ} \mathrm{C}$ (Garcia-Cela et al., 2019; Martín Castaño et al., 2017b). The baseline data in the driest treatments were different for each cereal type because of the inherent cereal respiration and differences in the natural contamination with mycobiota and toxigenic fungi. For shelled peanuts, which have a high lipid content, the respiration rates due to the presence of surface contamination would be lower than for some other temperate cereals. Figure 2 shows that temporal and total accumulated $\mathrm{CO}_{2}$ over the whole temperature range examined at a steady-state $a_{w}$ of 0.95 . The slowest respiration rates were observed at $20-25^{\circ} \mathrm{C}$ in the driest $a_{w}$ treatment tested over the 7 day storage period.

Statistically, there were significant differences between both naturally contaminated and inoculated peanuts with $A$. flavus under the different temperature $x a_{w}$ levels examined. The shelled peanuts inoculated with $A$. flavus had a higher respiration rates than the uninoculated naturally contaminated treatments. There were also statistically significant differences between the $a_{w}$ treatments. This implied that $a_{w}$ levels were more important in determining respiration rates and $\mathrm{CO}_{2}$ production than the storage $\mathrm{T}$.

\subsection{Effect of storage conditions on dry matter losses in naturally contaminated and} artificially inoculated shelled peanuts with $A$. flavus.

Figure 3 compares the effect of different temperature and $a_{w}$ treatments on the relative DMLs of natural and contaminated peanuts. There was an increase in DMLs, as the storage $a_{w}$ and temperature were increased. Statistical differences were found between both naturally contaminated shelled peanuts in relation to $a_{w}$ treatments (Chi-square $p<0.0001$ ). Previously, similar relationships were found for Fusarium graminearum colonisation of wheat and $A$. flavus colonisation of paddy and brown rice (Garcia-Cela et al., 2019; Martín Castaño et al., 2017b). In this study we have simulated natural contamination and high initial inoculum contaminated with $A$. flavus on shelled peanuts in order to evaluate the toxin production and elucidate the impacts related to the quality losses and mycotoxin contamination. This study has shown that DMLs were higher in the artificially inoculated treatments than the low naturally contaminated peanuts. The only exception was under relatively moist storage conditions at $35^{\circ} \mathrm{C}$ (14 vs $16 \%$ DML). Previously, optimum DMLs were found at $0.95 \mathrm{a}_{w}$ and $30-35^{\circ} \mathrm{C}$ in maize of about $17 \%$ after 10 days storage (Garcia-Cela et al., 2019). For paddy and brown rice inoculated with $A$. flavus DMLs were 3.5\% and 20\% respectively (Martín Castaño et al., 2017b). In this case, the unprocessed paddy rice was protected by the outer grain layers, decreasing the potential fungal colonisation when compared with the processed brown rice. In the present study, the DMLs values were the lowest at $<0.90 \mathrm{a}_{\mathrm{w}}$, even at $30-35^{\circ} \mathrm{C}$. Polynomial equations generated for both naturally and artificially contaminated shelled peanuts with the $\%$ DMLs are presented 
in Table 1. According to the model all terms except $\mathrm{T}^{2}$ were significant $(p$-value $<0.05)$, although the $R^{2}$ values were quite low.

Figure 4 shows the contour maps generated for the relationship between $a_{w} \times T$ and identifies the optimum and marginal conditions for DMLs in naturally and artificially contaminated peanuts. Higher DMLs were predicted in naturally contaminated peanuts due to $A$. flavus colonization between $20-30^{\circ} \mathrm{C}$.

Studies on shelled peanuts colonised by an aflatoxigenic strain of $A$. flavus over the temperature $\mathrm{x} \mathrm{a}_{\mathrm{w}}$ range of $15-42^{\circ} \mathrm{C}$ and $0.85-0.99 \mathrm{a}_{\mathrm{w}}$ highlight that $A$. flavus colonisation was lower when temperature was $\leq 20^{\circ} \mathrm{C}$ or $a_{w} \leq 0.85$ with optimum growth at $37^{\circ} \mathrm{C} / 0.98 a_{w}$ ( Liu et al., 2017). Previous research with $A$. flavus colonisation of peanuts have highlight an optimum growth temperature of $35^{\circ} \mathrm{C}$ and a minimum $a_{w}$ of 0.78 (Hill et al., 1983). Other studies have highlighted that for peanuts, the optimum $\mathrm{a}_{\mathrm{w}}$ range for $A$. flavus colonisation was $0.90-0.99 \mathrm{a}_{\mathrm{w}}$ (de Souza et al., 2014), while others have suggested that optima were at 0.90-0.95 $a_{w}$ (Horn, 2017). Other studies by Nakai et al. (2008) and Zorzete et al. (2011) suggested a minimum $a_{w}$ level for $A$. flavus growth in peanuts of $0.78-0.80 \mathrm{a}_{\mathrm{w}}$.

Previous ecophysiological studies have provided valuable data to build boundary models based on real time temperature and relative humidity in silos. The aim was to predict the specific risk of fungal spoilage in a specific commodity (Garcia-Cela et al., 2019). However, Garcia-Cela et al. (2018) have suggested that $\mathrm{CO}_{2}$ changes occur prior to temperature changes due to fungal activity and thus could provide a more sensitive earlier indication of risk.

On the other hand, according to our results (data no shown) and previous studies on stored oats have shown that higher populations of $F$. langsethiae (CFUs $\cdot g^{-1}$ ) were correlated with higher $\mathrm{R}$ rates (Mylona et al., 2011). It is noticeable that other indirect measurements like ergosterol or free fatty acid (FFA) could be used as an indicator of fungal contamination. However, the relationship between fungal populations and ergosterol is often unstable and related to mycelial biomass age (Dhingra et al., 2009). The relationship between FFA content and fungal contamination is controversial since some authors suggest that FFA changes in stored commodities such as soybean could partially be related to enzymatic activity of the soybeans instead of the fungal activity (Chapman and Robertson 1980). However, neither of thes methods can be applied in real time. They require samples to be removed from a silo and laboratory time to obtain a result. In contrast, the $\mathrm{CO}_{2}$ monitoring can be done in real time, which provides information on any changes in activity due to changes in moisture migration or 
temperature. It may be also possible to link the $\mathrm{CO}_{2}$ changes to the models for optimum and marginal conditions for toxin production.

3.3. Aflatoxin $B_{1}, B_{2}$ and cyclopiazonic acid production in shelled peanuts under different storage conditions

Figure 6 shows the effect of treatments on aflatoxins $B_{1}$ and $B_{2}$ and CPA. There were no significant differences in the mycotoxin contamination between naturally contaminated peanuts and that artificially inoculated with $A$. flavus (ChiSquare $p>0.0001$ ). AFB 1 contamination represented $>85 \%$ of the total AFs in the positive samples. A positive correlation $\left(r^{2}=0.9810\right)$ between the two types of AFs analysed (Spearman $\left.p<0.0001\right)$ was observed. Water activity significantly affected both $\mathrm{AFB}_{1}$ and $\mathrm{AFB}_{2}$ contamination (ChiSquare $\mathrm{p}<0.0001)$ in all treatments assayed. Aflatoxins were not detected at $0.85-0.90$ aw and $20^{\circ} \mathrm{C}$. Overall, the optimum temperature range for AFs production was between $25-30^{\circ} \mathrm{C}$. Previous studies have tried to evaluate the effect of environmental conditions on $\mathrm{AFB}_{1}$ accumulation by A. flavus. For example, Liu et al. (2017) found that the range of conditions for AFs production was $25-33^{\circ} \mathrm{C}$ and $0.92-0.96 \mathrm{a}_{\mathrm{w}}$, with a maximum at $28^{\circ} \mathrm{C} / 0.96 \mathrm{a}_{\mathrm{w}}$. Also, Abdel-Hadi et al. (2010) observed higher $\mathrm{AFB}_{1}$ production at 0.90-0.95 $\mathrm{a}_{\mathrm{w}}$. Regarding the minimum $\mathrm{a}_{\mathrm{w}}$ for toxin production, Passone et al. (2010) found $\mathrm{AFB}_{1}$ at 0.84-0.88 aw but only after longer storage periods (>1 month). However, these previous studies were carried out with irradiated relatively sterile peanuts inoculated with $A$. flavus. Thus, interactions with and presence of other mycobiota were not considered. Few studies have examined the production of CPA in relation to different storage conditions in peanuts or indeed in cereals generally. Storage temperature $x a_{w}$ significantly affected the production of CPA. However, CPA contamination was only detected in the wettest peanuts at 0.95 aw with optimum temperature conditions between 30$35^{\circ} \mathrm{C}$. Previously, Vaamonde et al. (2006) found that maximum accumulation of CPA was at $35^{\circ} \mathrm{C} / 0.94$ aw although some toxin was detected at $20^{\circ} \mathrm{C}$ and lower aw levels. Zorzete et al. (2017) monitored fungal populations and mycotoxin contamination of stored peanuts for 6 months and reported that $A$. flavus was predominant, with co-occurrence of AFs and CPA in $14 \%$ of the samples. It is thus important to try and monitor both toxins during the storage of groundnuts.

3.4. Relationship between dry matter losses and $\mathrm{AFB}_{1}$ accumulation on peanuts relative to the EU legislative limits for maximum contamination in food and feed The $\mathrm{AFB}_{1}$ data was plotted against DMLs for naturally contaminated shelled peanuts, and that inoculated with $A$. flavus in Figure 7. A significant positive correlation (Spearman $p<0.0001$ ) were found between the $\log _{10} A F B_{1}$ and $\log _{10} D M L$ in both naturally and artificially contaminated stored peanuts $\left(r^{2}=0.0 .7744\right.$ and $r^{2}=0.8464$, respectively). Figure 7 includes 
lines showing the $E U$ legislative limits for $\mathrm{AFB}_{1}$ in peanuts intended for human consumption $\left(8 \mu \mathrm{g} \mathrm{kg}^{-1}\right)$ and for animal feed $\left(20 \mu \mathrm{g} \mathrm{kg}^{-1}\right)$ (Commission, 2006, 2003). All treatments $>0.90$ $a_{w}(>15 \%$ m.c.) exceeded the EU legal limits. Overall, small losses in dry matter of $0.56 \%$ [DMLlog $\left.\log _{10}(-0.25)\right]$ resulted in $\mathrm{AFB}_{1}$ contamination above the legislative limits.

There appears to be a low tolerance for quality losses due to fungal spoilage in stored shelled peanuts, especially if they are not dried effectively. Indeed, because peanuts are hygroscopic they will often reabsorb moisture from the environment when post-harvest management is not effectively controlled. In previous studies with cereals, mycotoxin contamination of about $1 \%$ resulted in type $A$ and $B$ trichothecenes, zearalenone (both in wheat) and fumonisins toxin levels (maize) exceeded the EU legislative limits (Mylona and Magan, 2011; Mylona et al., 2012b; Garcia-Cela et al., 2018; 2019). For fatty acid rich nuts such as hazlenuts, Mylona (2012a) found that only $0.4 \%$ DML resulted in $\mathrm{AFB}_{1}$ contamination exceeding the EU limits. Thus, tolerances could be lower in nuts than for cereals. Unprocessed paddy rice offers some protection from fungal invasion and thus DMLs where mycotoxin contamination becomes a concern is higher than for brown rice where high DMLs occurred more rapidly in conjunction with higher $\mathrm{AFB}_{1}$ and fumonisins contamination (Martin Castano et al., 2017a,b). From the $\mathrm{CO}_{2}$ data sets it may be possible to develop three categories of low, intermediate, and high risks, relevant to human consumption or for animal feed use. Thus, this type of data could be utilised by silo Managers to help evaluate the temporal relative risk of mycotoxin contamination and take appropriate remedial action.

\section{Conclusions}

This study showed that it is possible to use production of $\mathrm{CO}_{2}$ as an early indicator of the onset of fungal colonisation or perhaps pest activity in stored peanuts. Small changes in DMLs resulted in $A F B_{1}$ levels exceeding the $E U$ legislative limits in food and feed. Contamination with CPA occurred over a narrower range of conditions than that for $\mathrm{AFB}_{1}$. Boundary conditions for colonisation and mycotoxin production could be effectively utilised to develop predictive models which can be used in conjunction with real-time $\mathrm{CO}_{2}$ production to improve post-harvest management of peanuts as an effective tool for improving management of stored commodities post-harvest. This could improve sustainability and reduce post-harvest waste streams from such commodities. 


\section{List of Figures}

a) Natural Peanuts at $30^{\circ} \mathrm{C}$

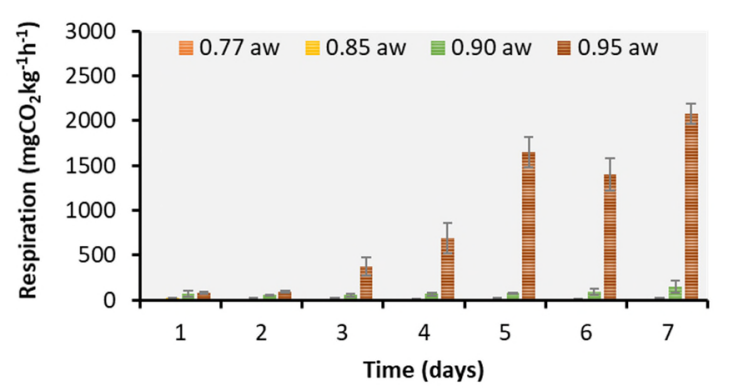

c) Natural Peanuts + A. flavus at $30^{\circ} \mathrm{C}$

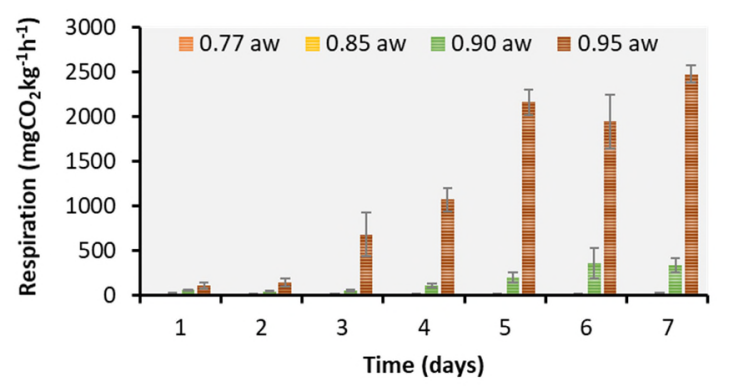

b) Natural Peanuts at $30^{\circ} \mathrm{C}$

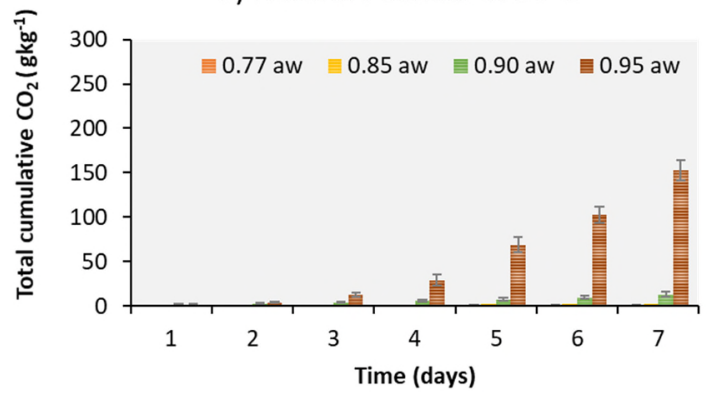

d) Natural Peanuts + A. flavus at $30^{\circ} \mathrm{C}$

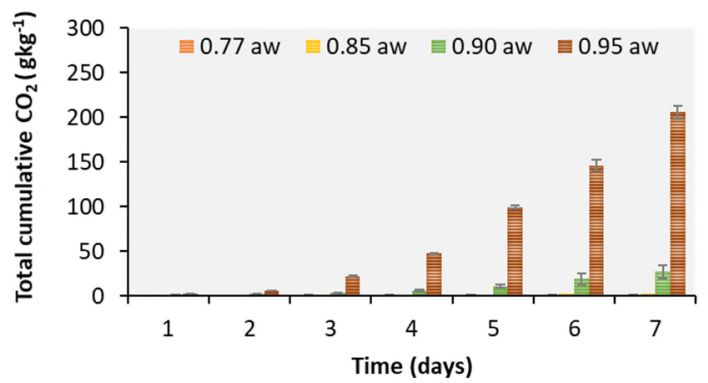

Figure 1. Temporal respiration $(\mathrm{R})(\mathrm{a}, \mathrm{c})$ and total accumulation (R cumulative) $(\mathrm{b}, \mathrm{d})$ of $\mathrm{CO}_{2}$ obtained from GC measurements in naturally contaminated peanuts and those inoculated with A. flavus at $30^{\circ} \mathrm{C}$ and stored for up to 7 days at four different $a_{w}$ levels. Vertical bars represent the standard error of the mean.

a) Natural Peanuts at $0.95 \mathrm{a}_{w}$

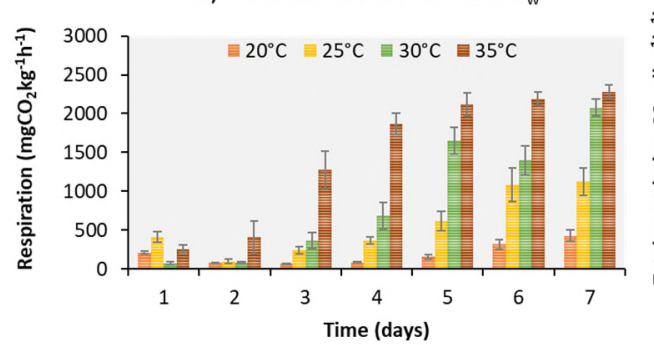

c) Natural Peanuts $+A$. flavus at $0.95 \mathrm{a}_{\mathrm{w}}$

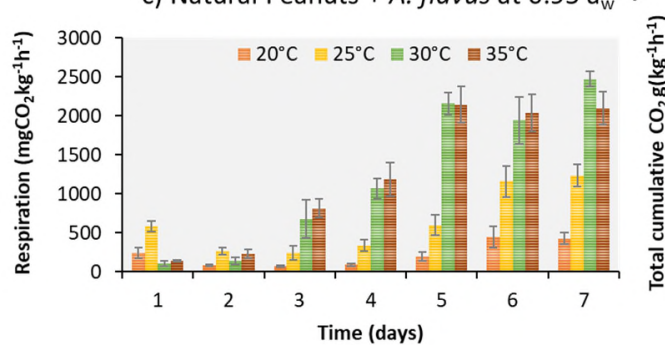

b) Natural Peanuts at $0.95 \mathrm{a}_{\mathrm{w}}$

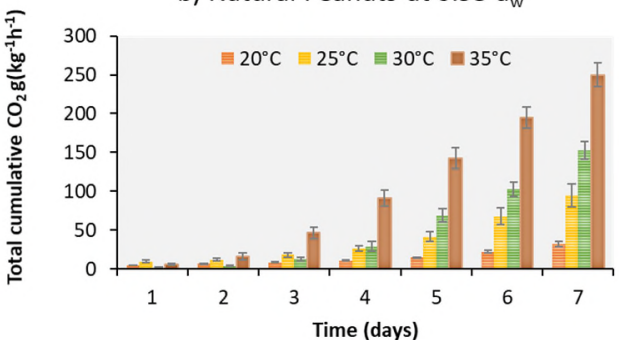

d) Natural Peanuts $+A$. flavus at $0.95 \mathrm{a}_{\mathrm{w}}$

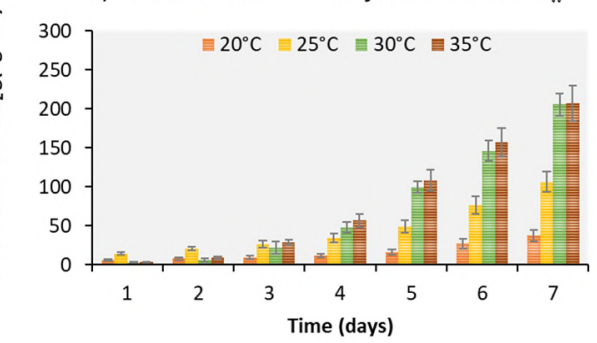

Figure 2. Temporal respiration (R) (a, c) and total accumulation (R cumulative) $(b, d)$ of $\mathrm{CO}_{2}$ obtained from GC measurements in naturally contaminated peanuts and those inoculated with A. flavus at $0.95 \mathrm{a}_{\mathrm{w}}$ level at four different temperatures over a 7 day storage period. Vertical bars represent the standard error of the mean. 
a) Natural Peanuts

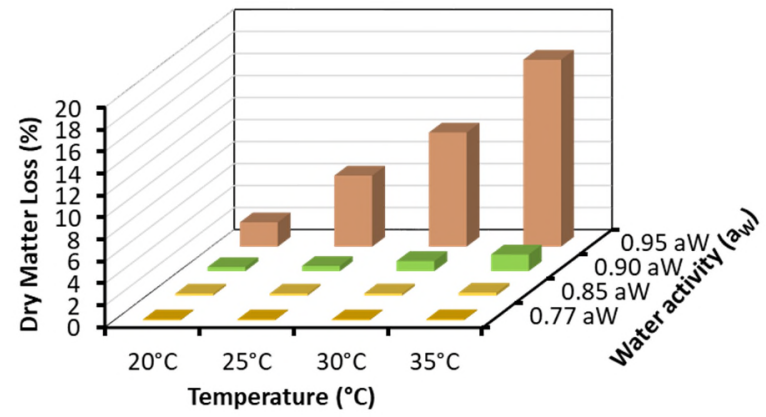

b) Natural Peanuts $+A$. flavus

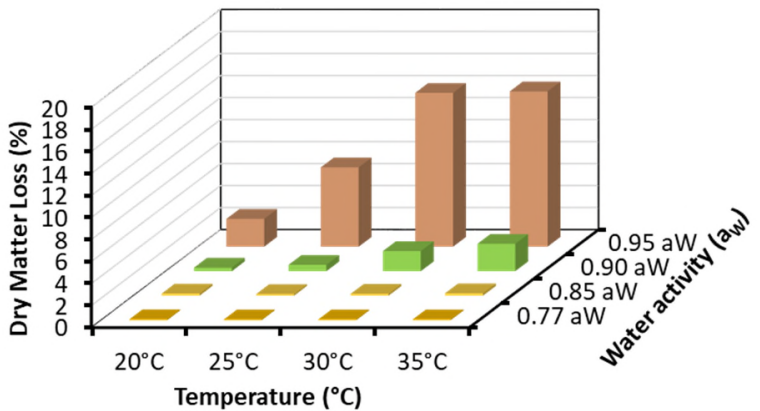

Figure 3. Percentage (\%) Dry Matter Losses (DMLs) calculated from the total accumulated $\mathrm{CO}_{2}$ production after 7 days in (a) naturally contaminated peanuts and (b) that inoculated with $A$. flavus spores and stored at different $a_{w}$ levels and different temperatures.

a) Natural Peanuts

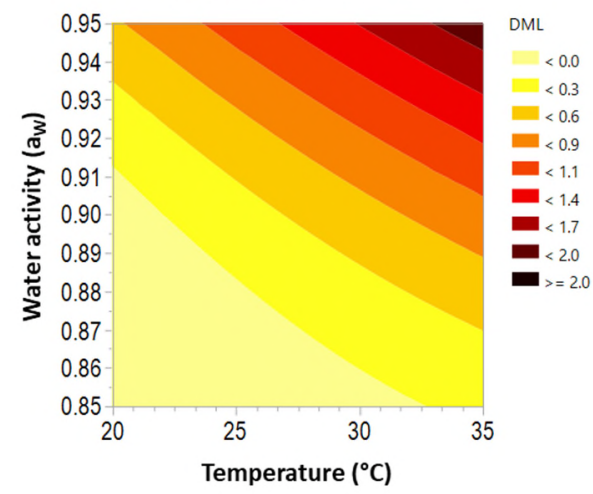

b) Natural Peanuts $+A$. flavus

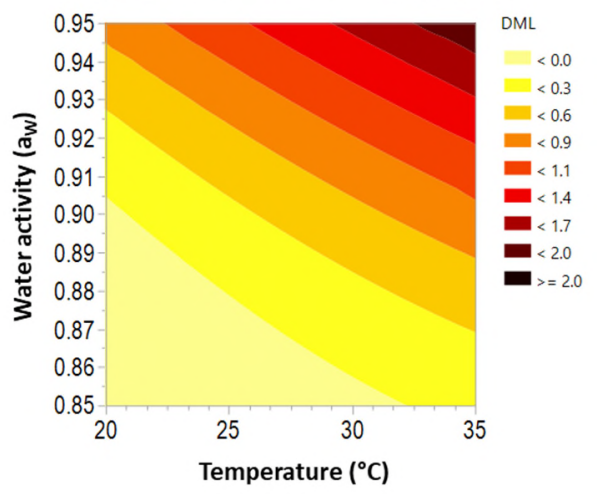

Figure 4. DMLs contour maps describing the relationship with different environmental parameters in (a) naturally contaminated and (b) that inoculated with $A$. flavus spores and stored under various combinations of environmental treatments.

a) Natural Peanuts

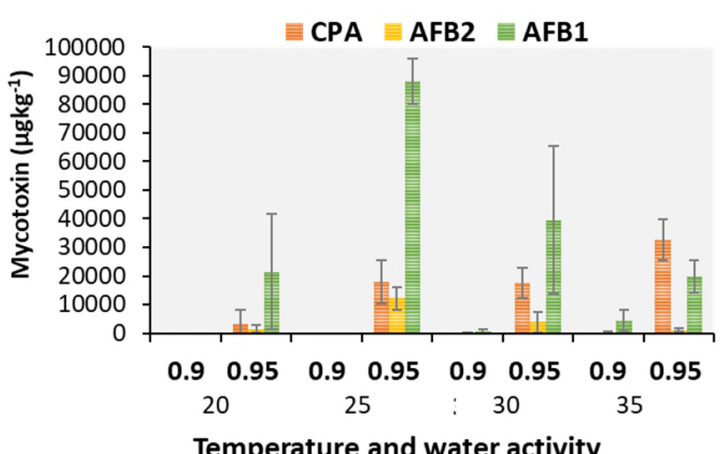

Temperature and water activity b) Natural Peanuts $+A$. flavus

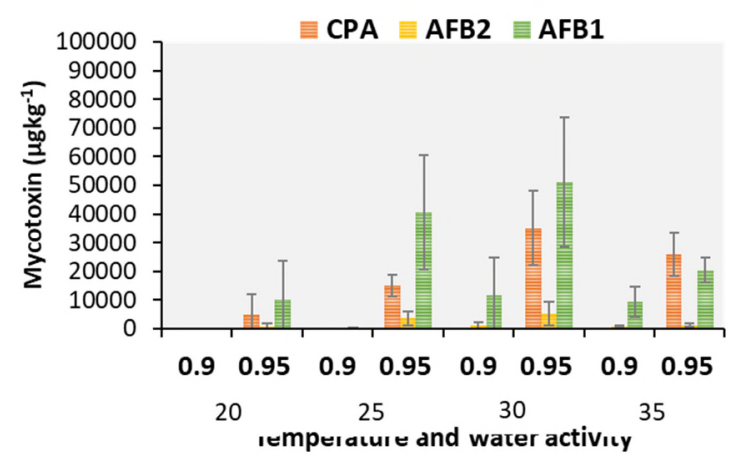

Figure 5. Mycotoxin contamination after 7 days in natural peanuts (a) and with $A$. flavus (b) and stored at different $a_{w}$ levels and different temperatures. Vertical bars represent the standard deviation of the mean. 

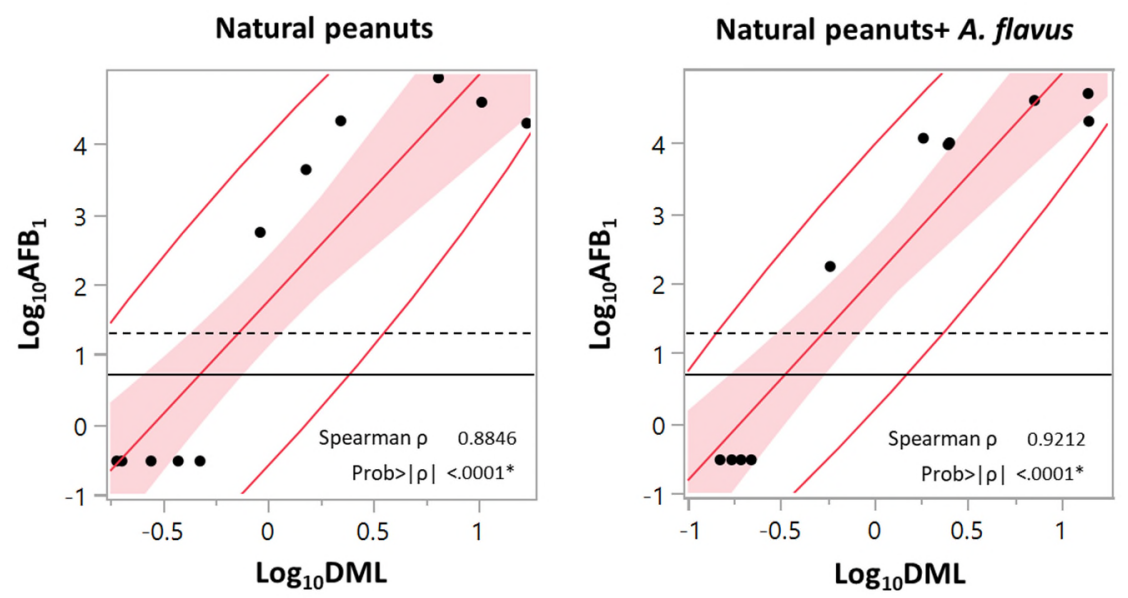

- Max $\mathrm{AFB}_{1}$ in raw peanuts EU, 1881/2006 $(8 \mu \mathrm{g} / \mathrm{kg})$

Animal Feed EU, 2003/100 $(20 \mu \mathrm{g} / \mathrm{kg})$

Figure 6: Scatter plot of DMLs and $\mathrm{AFB}_{1}$ in stored peanuts after 7 days storage under all the environmental conditions examined in (a) naturally contaminated peanuts and (b) peanuts inoculated with $A$. flavus. Horizontal lines represent EU legislative limits. Non-parametric Spearmans correlation Elipse $\alpha=0.95$ was used to analyse the data.

\section{Acknowledgements}

This project (MyToolBox) was funded from the European Union's Horizon 2020 research and innovation programme under grant agreement No. 678012. Partial funding was provided by the Newton Fund British Council Newton Fund Institutional Links project with Vietnam (Grant Number: 216265390).

Table 1. Estimated parameters from polynomial regression and maximum adjuster $r^{2}$ percentage (\%) DMLs

\section{Natural Peanuts}

\begin{tabular}{lrrlrrr} 
Parameter & Estimate & Std Error & p-value & Estimate & Std Error & p-value \\
\hline intercept & -7.820 & 0.407 & $<0.0001$ & -8.13 & 0.446 & $<0.0001$ \\
$\mathrm{~T}$ & 0.037 & 0.005 & $<0.0001$ & 0.035 & 0.005 & $<0.0001$ \\
$\mathrm{a}_{\mathrm{w}}$ & 7.779 & 0.429 & $<0.0001$ & 8.258 & 0.470 & $<0.0001$ \\
$\mathrm{~T}^{*} \mathrm{a}_{\mathrm{w}}$ & 0.662 & 0.073 & $<0.0001$ & 0.594 & 0.079 & $<0.0001$ \\
$\mathrm{a}_{\mathrm{w}}{ }^{2}$ & 87.446 & 7.381 & $<0.0001$ & 89.006 & 8.077 & $<0.0001$ \\
$\mathrm{r}^{2}$ & & 0.532 & & & 0.494 & \\
\hline
\end{tabular}

Only significant parameters have been included in the table.

Natural Inoculated Peanuts 


\section{References}

Abdel-Hadi, A., Carter, D., Magan, N., 2010. Temporal monitoring of the nor-1 (aflD) gene of Aspergillus flavus in relation to aflatoxin B1 production during storage of peanuts under different water activity levels. J. Appl. Microbiol. 109, 1914-1922. https://doi.org/10.1111/j.1365-2672.2010.04820.x

Atayde, D.D., Reis, T.A., Godoy, I.J., Zorzete, P., Reis, G.M., Corrêa, B., 2012. Mycobiota and aflatoxins in a peanut variety grown in different regions in the state of São Paulo, Brazil. Crop Prot. 33, 7-12. https://doi.org/10.1016/j.cropro.2011.11.013

Chapman, G. W., Robertson, J. A. 1980. The effect of soybean moisture during storage on the lipid composition of extracted crude oil. J. Am. Oil Chem. Soc. 57(10), 339-342.

Commission, E., 2006. Commission Regulation (EC) No. 1881/2006 of 19 December 2006, Setting maximum levels for certain contaminants in foodstuffs. Off. J. Eur. Union 364, $5-24$.

Commission, E., 2003. Commission Directive 2003/100/EC of 31 October 2003 amending Annex I to Directive 2002/32/EC of the European Parliament and of the Council on undesirable substances in animal feed (Text with EEA relevance). Off. J. L 285 , 01/11/2003 P. 0033 - 0037; L285, 0033-0037.

de Souza, G., Mossini, S., Galerani, Arrotéia, C., Kemmelmeier, C., Machinski, M., 2014. Evaluation of the mycoflora and aflatoxins from the pre-harvest to storage of peanuts :a case study. Acta Sci. - Agron. 36, 27-33. https://doi.org/10.4025/actasciagron.v36i1.16972

Dhingra, O. D., Jham, G. N., Rodrigues, F. A., Silva Jr, G. J., Costa, M. L. N. 2009. Fumigation with essential oil of mustard retards fungal growth and accumulation of ergosterol and free fatty acid in stored shelled groundnuts. J. Stored Prod. Res. 45(1), 24-31.

Fleurat-Lessard, F., 2017. Integrated management of the risks of stored grain spoilage by seedborne fungi and contamination by storage mould mycotoxins - An update. J. Stored Prod. Res. 71, 22-40. https://doi.org/10.1016/j.jspr.2016.10.002

Food and Agriculture Organisation of the United Nations, 2018. Data-Production-CropsWorld + total-Production Quantity-Groundnuts with shell-2016. [WWW Document]. FAOSTAT. URL http://www.fao.org/faostat/en/\#data/QC (accessed 8.26.18).

Garcia-Cela, E., Kiaitsi, E., Sulyok, M., Krska, R., Medina, A., Petit Damico, I., Magan, N., 2019. Influence of storage environment on maize grain: $\mathrm{CO}_{2}$ production, dry matter losses and aflatoxins contamination. Food Addit. Contam. Part A 36, 175-185. https://doi.org/10.1080/19440049.2018.1556403

Garcia-Cela, E., Kiaitsi, E., Sulyok, M., Medina, A., Magan, N., 2018. Fusarium graminearum in stored wheat: Use of $\mathrm{CO}_{2}$ production to quantify dry matter losses and relate this to relative risks of zearalenone contamination under interacting environmental conditions. Toxins (Basel). 10. https://doi.org/10.3390/toxins10020086

Garcia-Cela, E.; Kiaitsi, E.; Medina, A.; Rubio-Lopez, F.; Magan, N., 2018. $\mathrm{CO}_{2}$ production as early indicator of Pest and Fungal infestation: Effective for Post-harvest Decision Support System in stored Cereals. Poster 16 Sensors 2018. Innovative Chemical Sensing. London, United Kingdom. http://www.rsc.org/events/detail/31365/sensors2018-innovative-chemical-sensing

Gonçalez, E., Nogueira, J.H.C., Fonseca, H., Felicio, J.D., Pino, F.A., Corrêa, B., 2008. Mycobiota and mycotoxins in Brazilian peanut kernels from sowing to harvest. Int. J. Food Microbiol. 123, 184-190. https://doi.org/10.1016/j.ijfoodmicro.2008.01.012

Hill, R., Blankenshi, Paul, Cole, R., Sanders, T., 1983. Effects of Soil Moisture and Temperature on Preharvest Invasion of Peanuts by the Aspergillus flavus Group and Subsequent Aflatoxin Development 45, 628-633.

Horn, B., 2017. Colonization of wounded peanut seeds by soil fungi : selectivity for species from Aspergillus section Flavi Colonization of wounded peanut seeds by soil fungi: selectivity for species from Aspergillus section Flavi. Mycologia. 202-2017. https://doi.org/10.1080/15572536.2006.11832854

Lacey, J., Hamer, A., Magan, N., 1994. Respiration and dry matter losses in wheat grain 
under different environmental factors, in: Highley, E., Wright, E.J., Banks, H.J., Champ, B.R. (Eds.), In Stored Product Protection. pp. 1007-1013.

Liu, X., Guan, X., Xing, F., Lv, C., Dai, X., Liu, Y., 2017. Effect of water activity and temperature on the growth of Aspergillus flavus, the expression of aflatoxin biosynthetic genes and aflatoxin production in shelled peanuts. Food Control 82, 325-332. https://doi.org/10.1016/j.foodcont.2017.07.012

Magan, N., Aldred, D., Mylona, K. Lambert, R.J.M., 2010. Limiting mycotoxins in wheat. Food Addit Contam. 27, 644-650

Malachova, A., Sulyok, M., Beltran, E., Berthiller, F., Krska, R., 2015. Multi-Toxin Determination in Food - The Power of \&quot;Dilute and Shoot\&quot; Approaches in LC-MS-MS.

Malachová, A., Sulyok, M., Beltrán, E., Berthiller, F., Krska, R., 2014. Optimization and validation of a quantitative liquid chromatography-tandem mass spectrometric method covering 295 bacterial and fungal metabolites including all regulated mycotoxins in four model food matrices. J. Chromatogr. A 1362, 145-156. https://doi.org/10.1016/j.chroma.2014.08.037

Martín Castaño, S., Medina, A., Magan, N., 2017a. Impact of storage environment on respiration, dry matter losses and fumonisin B1 contamination of stored paddy and brown rice. World Mycotoxin J. 10, 319-326. https://doi.org/10.3920/WMJ2017.2237

Martín Castaño, S., Medina, A., Magan, N., 2017b. Comparison of dry matter losses and aflatoxin B1 contamination of paddy and brown rice stored naturally or after inoculation with Aspergillus flavus at different environmental conditions. J. Stored Prod. Res.73, 47-53. https://doi.org/10.1016/j.jspr.2017.06.004

Mylona, K., Magan, N., 2011. Fusarium langsethiae: Storage environment influences dry matter losses and T-2 and HT-2 toxin contamination of oats. J. Stored Prod. Res. 47, 321-327. https://doi.org/10.1016/j.jspr.2011.05.002

Mylona, K. 2012a. Fusarium species in grains: dry matter losses, mycotoxin contamination and control strategies using ozone and chemical compounds. PhD Thesis. Cranfield University, Cranfield, Beds. MK43 OAL, U.K.

Mylona, K., Sulyok, M., Magan, N., 2012b. Exposure \& Risk Assessment Relationship between environmental factors, dry matter loss and mycotoxin levels in stored wheat and maize infected with Fusarium species. Food Additives \& Contaminants : Part A: Chemistry, Analysis, Control, 37-41.

Nakai, V.K., de Oliveira Rocha, L., Gonçalez, E., Fonseca, H., Ortega, E.M.M., Corrêa, B., 2008. Distribution of fungi and aflatoxins in a stored peanut variety. Food Chem. 106, 285-290. https://doi.org/10.1016/j.foodchem.2007.05.087

Passone, M.A., Rosso, L.C., Ciancio, A., Etcheverry, M., 2010. Detection and quantification of Aspergillus section Flavi spp. in stored peanuts by real-time PCR of nor-1 gene, and effects of storage conditions on aflatoxin production. Int. J. Food Microbiol. 138, 276281. https://doi.org/10.1016/J.IJFOODMICRO.2010.01.003

Paterson, R., Lima, N., 2011. Further mycotoxin effects from climate change. Food Res. Int. 44, 2555-2566. https://doi.org/10.1016/j.foodres.2011.05.038

Saul, R.A., Lind, E.F., 1958. Maximum Time for Safe Drying of Grain With Unheated Air. Trans. ASAE 1, 0029-0033. https://doi.org/10.13031/2013.41203

Seitz, L., Sauer, D., Mohr, H., Aldis, D., 1982. Fungal Growth and Dry Matter Loss During Bin Storage of High-Moisture Corn. Cereal Chem.

Sultan, Y., Magan, N., 2010. Mycotoxigenic fungi in peanuts from different geographic regions of Egypt. Mycotoxin Res. 26, 133-140. https://doi.org/10.1007/s12550-0100048-5

Vaamonde, G., Patriarca, A., Pinto, V.E.F., 2006. Effect of water activity and temperature on production of aflatoxin and cyclopiazonic acid by Aspergillus flavus in peanuts, in: Advances in Experimental Medicine and Biology. pp. 225-235. https://doi.org/10.1007/0-387-28391-9_15

White, N.D.G., Sinha, R.N., Muir, W.E., 1982. Intergranuar carbon dioxide as an indicator of biological activity associated with the spoilage of stored wheat. 24, 35-42. 
Zorzete, P., Baquião, A., Atayde, D., Reis, T., Gonçalez, E., Corrêa, B., 2013. Mycobiota, aflatoxins and cyclopiazonic acid in stored peanut cultivars. Food Res. Int. 52, 380386. https://doi.org/10.1016/j.foodres.2013.03.029

Zorzete, P., Reis, T.A., Felício, J.D., Baquião, A.C., Makimoto, P., Corrêa, B., 2011. Fungi, mycotoxins and phytoalexin in peanut varieties, during plant growth in the field. Food Chem. 129, 957-964. https://doi.org/10.1016/j.foodchem.2011.05.053

Zorzete, P., Baquião, A.C., Atayde, D.D., Reis, T.A., Gonçalez, E., \& Corrêa, B., 2013. Mycobiota, aflatoxins and cyclopiazonic acid in stored peanut cultivars. Food Res Int, 52(1), 380-386. 